\title{
Corticotomy-Assisted Orthodontic Treatment: Review
}

\author{
Ali H. Hassan ${ }^{*,}$, Ahmad A. Al-Fraidi ${ }^{2}$ and Samar H. Al-Saeed ${ }^{2}$ \\ ${ }^{1}$ Saudi Board in Orthodontics- Western Region, Saudi Arabia. Faculty of Dentistry, King Abdulaziz University, Jeddah, \\ Saudi Arabia \\ ${ }^{2}$ Saudi Board in Orthodontics, King Abdulaziz University, Faculty of Dentistry, Jeddah, Saudi Arabia
}

\begin{abstract}
Corticotomy-assisted orthodontic treatment is an established and efficient orthodontic technique that has recently been studied in a number of publications. It has gradually gained popularity as an adjunct treatment option for the orthodontic treatment of adults. It involves selective alveolar decortication in the form of decortication lines and dots performed around the teeth that are to be moved. It is done to induce a state of increased tissue turnover and a transient osteopenia, which is followed by a faster rate of orthodontic tooth movement. This technique has several advantages, including faster tooth movement, shorter treatment time, safer expansion of constricted arches, enhanced post-orthodontic treatment stability and extended envelope of tooth movement. The aim of this article is to present a comprehensive review of the literature, including historical background, contemporary clinical techniques, indications, contraindications, complications and side effects.
\end{abstract}

Keywords: Corticotomy, decortication, review, orthodontic treatment.

\section{INTRODUCTION}

An increasing number of adult patients are seeking orthodontic treatment [1]. There are several psychological, biological and clinical differences between the orthodontic treatment of adults and adolescents. Adults have more specific objectives and concerns related to facial and dental aesthetics, the type of orthodontic appliance and the duration of treatment. Growth is an almost insignificant factor in adults compared to children, and there is increasing chance that hyalinization will occur during treatment [2]. In addition, cell mobilization and conversion of collagen fibers is much slower in adults than in children. Finally, adult patients are more prone to periodontal complications since their teeth are confined in non-flexible alveolar bone [2]. These considerations make orthodontic treatment of adults different and challenging as well as necessitate special concepts and procedures, such as the use of invisible appliances, shorter periods of treatment, the use of lighter forces and more precise tooth movements.

The development of corticotomy-assisted orthodontic treatment (CAOT) opened doors and offered solutions to many limitations in the orthodontic treatment of adults. This method claims to have several advantages. These include a reduced treatment time, enhanced expansion, differential tooth movement, increased traction of impacted teeth and, finally, more post-orthodontic stability. The evidence of the success of corticotomy as an adjunct to orthodontic treatment has not been well documented, and few published reports are

*Address correspondence to this author at the P.O. Box 80209, Jeddah 21589, Preventive Dental Science Department, Faculty of Dentistry, King Abdulaziz University, Jeddah, Saudi Arabia; Tel: 9662 6401000; Fax: 966 2 6403316; E-mails: aliresearch@gawab.com; alihabib169@hotmail.com available. The aim of this article is to present a comprehensive review of the literature, including the historical background, the contemporary clinical techniques, indications, contraindications, complications and side effects.

\section{HISTORICAL BACKGROUND}

Corticotomy has roots in orthopedics going back to the early 1900s. In 1892, it was first defined as a linear cutting technique in the cortical plates surrounding the teeth to produce mobilization of the teeth for immediate movement [3]. Köle introduced a surgical procedure involving both osteotomy and corticotomy to accelerate orthodontic tooth movement, based on the concept that teeth move faster when the resistance exerted by the surrounding cortical bone is reduced via a surgical procedure. Köle further explained that the reduced resistance enhances an en bloc movement of the entire alveolar cortical segment, which is connected by softer medullary bone, including the confined teeth, when exposed to orthodontic forces [4]. This theory of en bloc movement to enhance tooth movement prevailed in several subsequent reports [5-8]. Suya specified that most orthodontic treatments should be completed in the first three to four months after corticotomy and before fusion of the tooth-bone units [7]. Generson et al. reported about cases treated using a corticotomy-only technique for accelerated tooth movement, which led to successful results [8].

Frost [9] found a direct correlation between the severity of bone corticotomy and/or osteotomy and the intensity of the healing response, leading to accelerated bone turnover at the surgical site. This was designated "Regional Acceleratory Phenomenon" (RAP). RAP was explained as a temporary stage of localized soft and hard-tissue remodeling that resulted in rebuilding of the injured sites to a normal state through recruitment of osteoclasts and osteoblasts via local intercellular mediator mechanisms involving precursors, 
supporting cells, blood capillaries and lymph [10]. This accelerated remodeling is influenced by bone density and the hyalinization of the periodontal ligament (PDL) [11-14].

\section{Contemporary Clinical Techniques}

Recently, Wilcko developed a patented technique called Accelerated Osteogenic Orthodontics (AOO) [15] or Periodontally Accelerated Osteogenic Orthodontics (PAOO) [16]. This technique is similar to conventional corticotomy except that selective decortication in the form of lines and points is performed over all of the teeth that are to be moved. In addition, a resorbable bone graft is placed over the surgical sites to augment the confining bone during tooth movement. After a healing period of one or two weeks, orthodontic tooth movement is started and then followed up using a faster rate of activation at two week intervals $[15,16]$.

Using this technique, Wilcko [15-17] reported rapid tooth movement at a rate of 3 to 4 times greater than conventional orthodontic movement, which was attributed to a state of reduced mineralization (reversible osteopenia) of the alveolar bone surrounding the involved teeth during the orthodontic movement and not to bony block movement, as claimed by Köle [15-17]. Wilcko explained the concept of reversible osteopenia in a study of five patients using computed tomographic imaging [17]. After corticotomy, demineralization occurs in the alveolar bone and the remaining collagenous matrix of the bone is transported with the tooth during its movement. The matrix then remineralizes after the orthodontic movement. This introduced new concepts to the CAOT field, including bone matrix transportation and osteopeniafacilitated rapid tooth movement [17].

The evidence presented in support of CAOT thus far is case report studies, which is considered weak evidence to support the purported advantages and the mechanism of action.

Recent animal studies have added more evidence to the effect of CAOT. Ren et al. [18] evaluated the effects of alveolar interseptal corticotomy and extraction on orthodontic tooth movement in beagles. The tooth on the experimental side moved more rapidly than the tooth on the control side, without any associated root resorption or irreversible pulp injury. In addition, active and extensive bone remodeling around the moved tooth was shown. Mostafa et al. [19] reported a doubled rate of tooth movement after corticotomy in dogs and attributed this to the observed increase in bone turnover and the RAP phenomenon. In another animal study using CAOT, the third premolar was mesialized significantly faster than the control side in 12 dogs. Cortictomy was found to increase tooth movement for at least 2 weeks after the surgery and to limit the hyalinization of the periodontal ligaments on the alveolar wall to the first week after corticotomy. This was also attributed to a rapid alveolar bone reaction [20].

Two recent histological studies were conducted to evaluate tissue response to decortication [21,22]. Sebaoun et al. [21] evaluated the response of alveolar bone to a selective alveolar decortication in a rat model in terms of time and proximity to the site of decortication without attempting any type of tooth movement. This study demonstrated an increased turnover of alveolar spongiosa as a response to al- veolar decortication. Three weeks after surgery, the catabolic activity (osteoclast count) and anabolic activity (apposition rate) were three times greater, calcified spongiosa decreased by two-fold and PDL surface increased by two-fold. This dramatic increase in bone turnover decreased to a steady state by the eleventh week after surgery. The observed effect of corticotomy was localized to the area immediately adjacent to the decortication cuts.

In the other histological study, Wang et al. [22] explained the sequence of events occurring after corticotomy in rats. CAOT was compared to osteotomy-assisted tooth movement and to controls. Corticotomy was found to produce bone resorption around the moving teeth by day 21 after surgery and the area refilled with bone after 60 days. This confirms the occurrence of reversible osteopenia during CAOT.

\section{The CAOT Technique}

Case selection is a very important step; both the orthodontist and the periodontist should agree upon the need for corticotomy, treatment plan and the extent and location of the decortication cuts. The PAOO technique described by Wilcko is as follows [23]: full-thickness flaps are reflected labially and lingually using sulcular releasing incisions. The releasing incision can also be made within the thickness of the gingival attachment or at the base of the gingival attachment (mucogingival junction). Vertical releasing incisions can be used, but they should be positioned at least one tooth away from the "bone activation". Flaps should be carefully reflected beyond the apices of the teeth to avoid damaging the neurovascular complexes exiting the alveolus and to allow adequate decortication around the apices. Selective alveolar decortication is performed in the form of decortication cuts and at points up to $0.5 \mathrm{~mm}$ in depth, combined with selective medullary penetration to enhance bleeding. This poses little threat to tooth vitality and makes PAOO much safer than the osteotomy technique, in which cuts extend into the medullary bone around the teeth that are to be moved. Adequate bio-absorbable grafting material is placed over the injured bone. Flaps are then repositioned and sutured into place. Sutures should be left in place for a minimum of two weeks. Tooth movement should start one or two weeks after surgery. Unlike conventional orthodontics, the orthodontic appliance should be activated every two weeks until the end of treatment after PAOO (Fig. 1a, b, c).

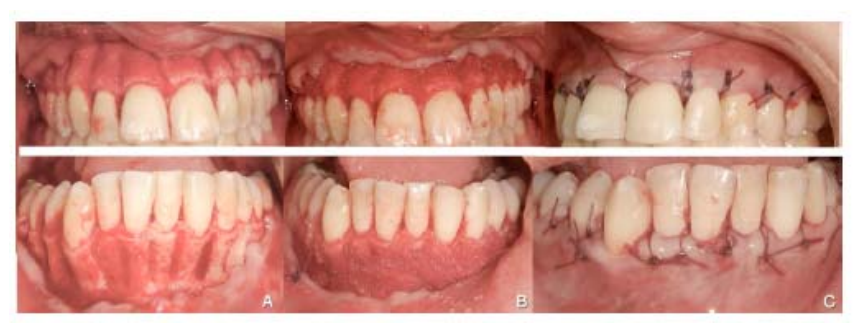

Fig. (1a). A full thickness flap is reflected and selective alveolar decortication is performed in the form of decortication cuts and points up to $0.5 \mathrm{~mm}$ in depth. 1b) Bio-absorbable grafting material is placed over the injured bone. 1c) Flaps are then repositioned and sutured into place. 


\section{Indications and Clinical Applications}

Several clinical applications for CAOT have been reported. Corticotomy was used to facilitate orthodontic tooth movement and to overcome some shortcomings of conventional orthodontic treatment, such as the long required duration, limited envelope of tooth movement and difficulty of producing movements in certain directions. These applications include the following:

\section{Resolve Crowding and Shorten Treatment Time}

Corticotomy and osteotomy were used in orthodontics primarily to resolve crowding in a shorter period of time. Several authors have described cases in which moderate and severe crowding was treated without extraction by corticotomy/osteotomy-assisted orthodontics and in shorter periods of time [15-17, 24]. It has been shown that corticotomy is efficient in reducing the treatment time to as little as onefourth the time usually required for conventional orthodontics [17]. Wilcko published a report about two adult patients with severe crowding who were treated via AOO in just 6.5 months [17]. Wilcko also reported a case of an adult female who was treated in only 4.5 months [16]. Hajji [24] studied the effects of resolving mandibular anterior dental crowding by comparing non-extraction $(\mathrm{n}=30)$, extraction $(\mathrm{n}=34)$, and corticotomy-facilitated non-extraction $(n=20)$ orthodontic treatments in a clinical trial. The mean active treatment time for the corticotomy-facilitated group was 6.1 months, versus 18.7 months required for non-extraction orthodontics and 26.6 months for extraction therapy. A reduced chance of root resorption [25, 26], less oral hygienerelated enamel decalcification and better patient cooperation and acceptance are possible advantages when lengthy orthodontic treatment is avoided.

\section{Accelerate Canine Retraction after Premolar Extrac- tion}

Canine retraction after premolar extraction is a lengthy step during the extraction stage of orthodontic treatment. Canine retraction was accelerated by corticotomy in two animal studies. Both studies demonstrated faster canine retraction when compared to conventional orthodontic retraction of the canines [18-19].

\section{Enhance Post-Orthodontic Stability}

Stability after orthodontic treatment may not always be achievable. Little has shown that 10 years after orthodontic treatment, only $30 \%$ of patients had satisfactory alignment of the mandibular incisors [27]. Stability was reported as one of the advantages of corticotomy-assisted orthodontics [24]. Corticotomy-facilitated orthodontic treatment was found to result in better retention compared to conventional orthodontic treatment $[24,28]$. The improved stability was attributed to the increased turnover of tissues adjacent to the surgical site. Unfortunately, there is still no strong evidence for enhanced stability after CAOT in the literature. Definitive conclusions cannot be made unless prospective controlled studies are conducted.

\section{Facilitate Eruption of Impacted Teeth}

Surgical traction of impacted teeth, especially the canines, is a frustrating and lengthy procedure. A study by
Fischer [29] showed that under the same periodontal conditions, the corticotomy-assisted approach produced faster tooth movement during traction of palatally impacted canines compared to conventional canine traction methods at the end of either treatment. In an adult female patient, an impacted second premolar was facilitated to erupt spontaneously using corticotomy after creating enough space as a part of an overall fixed orthodontic treatment, which included extraction of the first premolars and bilateral corticotomyassisted expansion. Spontaneous eruption was completed in three months without any orthodontic traction (Figs. 2 and 3).

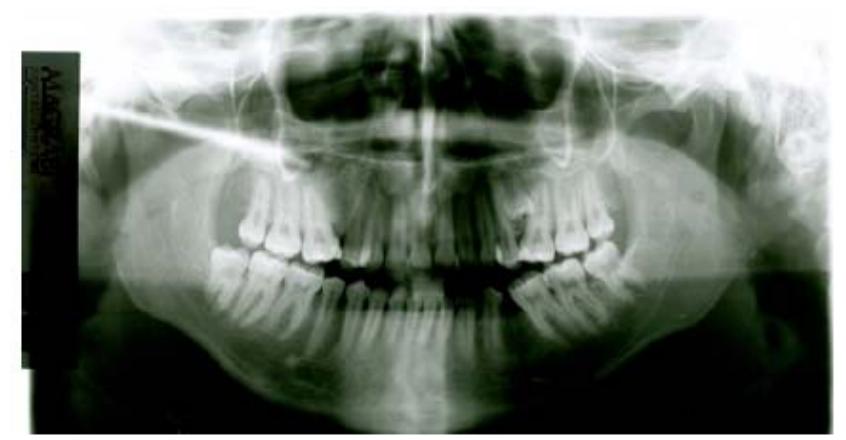

Fig. (2). Pre-treatment panoramic radiograph of a female patient showing an impacted upper left second premolar.

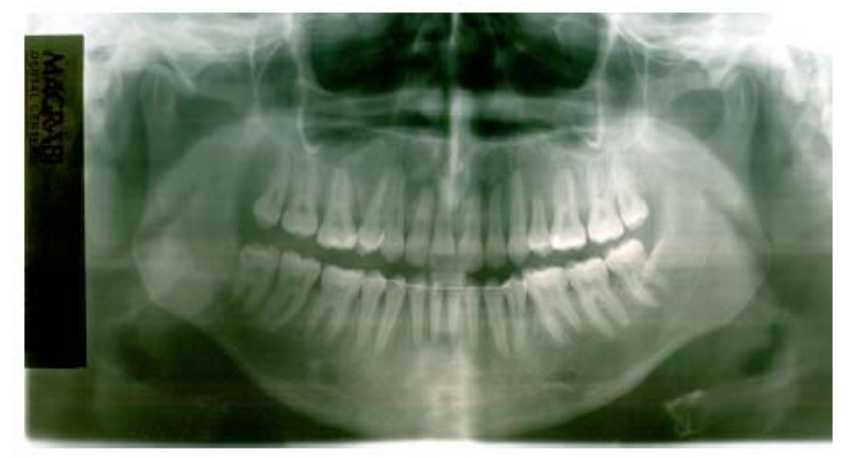

Fig. (3). Post treatment panoramic radiograph of the same patient in figure 2 , showing the fully erupted second premolar after $\mathrm{CAE}$, extraction of the adjacent first premolar and fixed orthodontic treatment.

\section{Facilitate Slow Orthodontic Expansion}

A limited number of successful techniques is available for the treatment of maxillary arch constriction; these include surgically-assisted rapid palatal expansion (SARPE) and slow palatal expansion. These techniques are aggressive in nature and less accepted by patients. The presence of nongrowing alveolar bone that confines the teeth in the predetermined space available in the alveolus limits transverse tooth movement [30]. Yen et al. reported a cleft patient with palatal constriction in the upper arch who was treated via corticotomy assisted expansion (CAE) after surgical closure of a palatal fistula [31]. CAE is an effective technique for the treatment of maxillary transverse deficiency in adults and is assumed to provide greater stability and better periodontal health than conventional expansion, which can be less effective, dangerous and unstable in many patients. In addition, CAE allows differential expansion as well as unilateral ex- 
pansion in a more controlled way than conventional expansion. Figs. (4 and 5) present a case of severely constricted maxilla that was expanded using a quad-helix appliance assisted by bilateral buccal and palatal decortication. Successful expansion of the upper arch was achieved; the inter-molar distance was increased by $5 \mathrm{~mm}$, and the inter-canine distance was increased by $4 \mathrm{~mm}$.

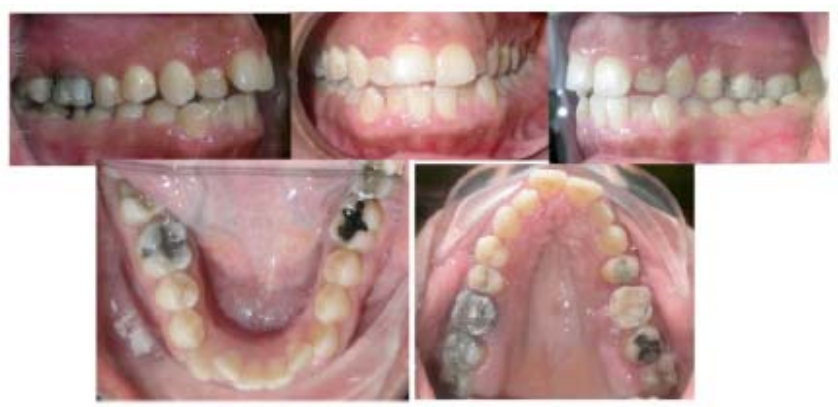

Fig. (4). Pre-treatment intra-oral photographs of an adult female patient having a severe bilateral cross-bite treated by CAE and fixed orthodontic appliance.

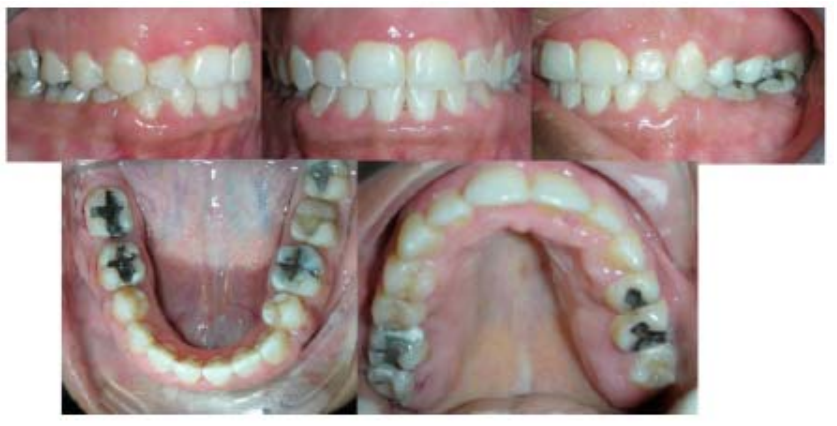

Fig. (5). Post-treatment intra-oral photographs of the same patient seen in Fig. (4).

CAE can be a good alternative to conventional orthodontic mechanics in the treatment of unilateral cross-bites in adults, which are either less efficient, patient-dependent, or accompanied by unnecessary side effects such as overexpansion on the normal side, canting of the occlusal plane and compromised vertical dimension [32, 33]. Performing corticotomy on only the constricted side helps to overcome these unnecessary side effects. The decorticated side is assumed to exhibit reduced resistance to expansion and faster tooth movement, making the effect of any bilateral expansion appliance unilateral. Figs. (6 and 7) show a case with a true unilateral cross-bite treated efficiently in 15 months using a quad-helix appliance assisted by unilateral right buccal and palatal decortications and fixed orthodontic appliance.

\section{Molar Intrusion and Open Bite Correction}

CAOT has also been used in the treatment of severe anterior open bite in conjunction with skeletal anchorage [34, 35]. Moon et al. achieved sufficient maxillary molar intrusion (3.0 mm intrusion in two months) using corticotomy combined with a skeletal anchorage system with no root resorption and with no patient compliance required [35]. Olivieria et al. [36] also reported $4 \mathrm{~mm}$ of molar intrusion in 2.5 months using corticotomy in one patient and 3 to $4 \mathrm{~mm}$ in 4 months in another patient. Hawang and Lee [37] demon-

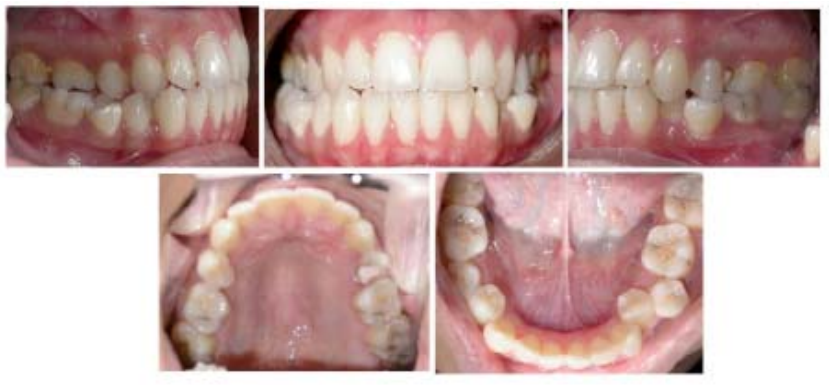

Fig. (6). Pre-treatment intra-oral photographs of an adult female patient having a unilateral cross-bite, treated by unilateral CAE and fixed orthodontic treatment.

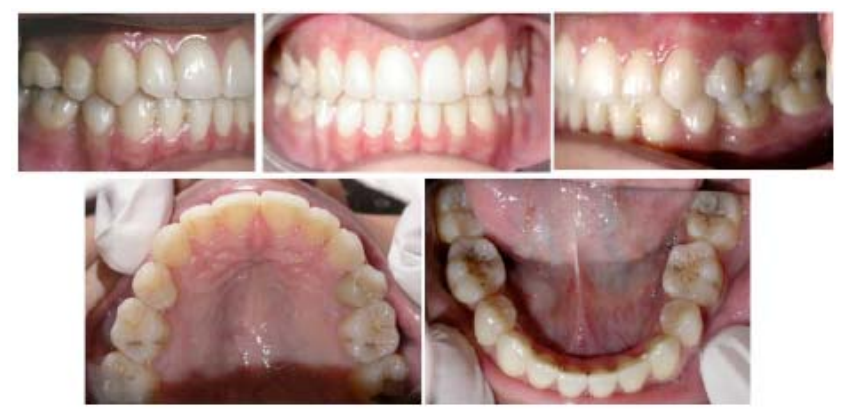

Fig. (7). Post-treatment intra-oral photographs of the patient seen in Fig. (6).

strated intrusion of supra-erupted molars using corticotomy, full-time use of magnetic appliances and night-time use of a vertical-pull chin-cup.

Intrusion can also be obtained using other orthodontic treatment approaches without selective corticotomies; however, this requires a longer active treatment time. Yao et al. [38] achieved a $4 \mathrm{~mm}$ molar intrusion using skeletal anchorage in 7.6 months. Sherwood et al. [39] obtained a $4 \mathrm{~mm}$ intrusion in 6.5 months using mini-titanium plates, and Enacar et al. [40] registered approximately $4 \mathrm{~mm}$ intrusion in 8.5 months.

\section{Manipulation of Anchorage}

CAOT was used in the treatment of bimaxillary protrusion as an adjunct to manipulate skeletal anchorage without any adverse side effects in only one-third of the regular treatment time [41].

CAOT was also used to achieve molar distalization. After performing segmental corticotomy around the molars, the anchorage value and resistance of the molars to distal movement were effectively reduced without the use of any extra anterior anchorage devices [42].

\section{Contraindications and Limitations}

Patients with active periodontal disease or gingival recession are not good candidates for CAOT. In addition, CAOT should not be considered as an alternative for surgically assisted palatal expansion in the treatment of severe posterior cross-bite. CAOT also should not be used in cases where bimaxillary protrusion is accompanied with a gummy smile, which might benefit more from segmental osteotomy [43]. 


\section{Complications and Side Effects}

Although CAOT may be considered a less-invasive procedure than osteotomy-assisted orthodontics or surgically assisted rapid expansion, there have still been several reports regarding adverse effects to the periodontium after corticotomy, ranging from no problems $[8,41,44]$ to slight interdental bone loss and loss of attached gingiva [45], to periodontal defects observed in some cases with short interdental distance [46]. Subcutaneous hematomas of the face and the neck have been reported after intensive corticotomies [6, 47]. In addition, some post-operative swelling and pain is expected for several days.

No effect on the vitality of the pulps of the teeth in the area of corticotomy was reported [47]. Long-term research on pulpal vitality after rapid movement has not been evaluated in the literature. In an animal study, Liou et al. [48] demonstrated normal pulp vitality after rapid tooth movement at a rate of $1.2 \mathrm{~mm}$ per week. However, pulp vitality deserves additional investigation.

It is generally accepted that some root resorption is expected with any orthodontic tooth movement [49]. An association between increased root resorption and duration of the applied force was reported [50-52]. The reduced treatment duration of CAOT may reduce the risk of root resorption. Ren et al. [18] reported rapid tooth movement after corticotomy in beagles without any associated root resorption or irreversible pulp injury. Moon et al. reported safe and sufficient maxillary molar intrusion $(3.0 \mathrm{~mm}$ intrusion in two months) using corticotomy combined with a skeletal anchorage system with no root resorption [35]. Long-term effect of $\mathrm{CAOT}$ on root resorption requires further study.

\section{CONCLUSION}

CAOT is a promising technique that has many applications in the orthodontic treatment of adults because it helps to overcome many of the current limitations of this treatment, including lengthy duration, potential for periodontal complications, lack of growth and the limited envelope of tooth movement. The mechanism behind CAOT can be summarized as the induction of bone metabolism via decortication lines and points around the teeth to be moved to enhance bone and periodontal turnover, resulting in a transient stage of osteopenia during treatment. This enhances and accelerates tooth movement if followed by a short period of orthodontic appliance treatment. PAOO effects and mechanism were confirmed by recent well designed histological studies. However, further randomized testing in humans is still needed to confirm the claimed advantages of this technique and to evaluate the long term effects.

\section{REFERENCES}

[1] Mathews DP, Kokich VG. Managing treatment for the orthodontic patient with periodontal problems. Semin Orthodont 1997; 3: 2138.

[2] Ong MM, Wang HL. Periodontic and orthodontic treatment in adults. Am J Orthodont Dentofacial Orthoped 2002 ; 122: 420-28.

[3] Fitzpatrick Barry N. Corticotomy. Aust Dent J 1980; 25: 255-58.

[4] Kole H. Surgical operation on the alveolar ridge to correct occlusal abnormalities. Oral Surg Oral Med Oral Pathol Oral Radiol Endod 1959; 12: 515-29.

[5] Anholm M CD, Crites D, Hoff R, Rathbun E. Corticotomyfacilitated orthodontics. Calif Dent Assoc J 1986; 7: 8-11.
[6] Gantes B, Rathbun E, Anholm M. Effects on the periodontium following corticotomy-facilitated orthodontics: case reports. J Periodontol 1990; 61: 234-8.

[7] Suya H. Corticotomy in orthodontics. In: Hosl E, Baldauf A, Eds. Mechanical and biological basics in orthodontic therapy. Heidelberg, Germany: Huthig Buch Verlag; 1991; p. 207-26.

[8] Duker J. Experimental animal research into segmental alveolar movement after corticotomy. J Maxillofac Surg 1975; 3: 81-4.

[9] Frost HM. The regional accelerated phenomenon. Orthop Clin N Am 1981; 12: 725-6.

[10] Yaffe A, Fine N, Binderman I. Regional accelerated phenomenon in the mandible following mucoperiosteal flap surgery. J Periodontol 1994; 65: 79-83.

[11] Verna C, Dalstra M, Melsen B. The rate and the type of orthodontic tooth movement is influenced by bone turnover in a rat model. Eur J Orthod 2000; 22: 343-52.

[12] Verna C, Melsen B. Tissue reaction to orthodontic tooth movement in different bone turnover conditions. Orthod Cranio fac Res 2003; 6: 155-63.

[13] Goldie RS, King GJ. Root resorption and tooth movement in orthodontically treated, calcium-deficient, and lactating rats. Am J Orthod 1984; 85: 424-30.

[14] Bohl MV, Maltha JC, Von den Hoff JW, Kuijpers-Jagtman AM. Focal hyalinization during experimental tooth movement in beagle dogs. Am J Orthod Dentofacial Orthop 2004; 125: 615-23.

[15] Wilcko WM, Wilcko MT, Bouquot JE, Ferguson DJ. Rapid orthodontics with alveolar reshaping: two case reports of decrowding. Int J Periodontics Restorative Dent 2001; 21: 9-19.

[16] Wilcko MT, Wilcko WM, and Nabil F. Bissada . An evidencebased analysis of periodontally accelerated orthodontic and osteogenic techniques: a synthesis of scientific perspectives. Semin Orthod 2008; 14: 305-16.

[17] Wilcko WM, Ferguson DJ, Bouquot JE, Wilcko MT. Rapid orthodontic decrowding with alveolar augmentation: case report. World J Orthod 2003; 4: 197-205.

[18] Ren A, Lv T, Zhao B, Chen Y, Bai D. Rapid orthodontic tooth movement aided by alveolar surgery in beagles. Am J Orthod Dentofacial Orthop 2007; 131: 160.e1-10.

[19] Mostafa YA, Fayed MM, Mehanni S, ElBokle NN, Heider AM. Comparison of corticotomy-facilitated vs standard tooth-movement techniques in dogs with miniscrews as anchor units. Am J Orthod Dentofacial Orthop 2009; 136: 570-7.

[20] Ino S, Sakoda S, Ito G, Nishimori T, Ikeda T, Miyawaki S. Acceleration of orthodontic tooth movement by alveolar corticotomy in the dog. Am J Orthod Dentofacial Orthop 2007; 131: 448.e1448.e8

[21] Sebaoun JD, Kantarci A, Turner JW, Carvalho RS, Van Dyke TE, Ferguson DJ. Modeling of trabecular bone and lamina dura following selective alveolar decortication in rats. J Periodontol 2008; 79: 1679-88.

[22] Lei Wang L, Lee W, Lei DL, Liu YP, Yamashita DD, Yen SL. Tisssue responses in corticotomy- and osteotomy-assisted tooth movements in rats: Histology and immunostaining. Am J Orthod Dentofacial Orthop 2009; 136: 770.e1-11.

[23] Wilcko MT, Wilcko WM, Pulver JJ, Bissada NF, Bouquot JE. Accelerated osteogenic orthodontics technique: a 1-Stage surgically facilitated rapid orthodontic technique with alveolar augmentation. J Oral Maxillofac Surg 2009; 67: 2149-59.

[24] Hajji SS. The influence of accelerated osteogenic response on mandibular de- crowding [thesis]. St Louis: St Louis Univ, 2000.

[25] Machado I, Ferguson DJ, Wilcko WM, Wilcko MT, AlKahadra T. Root resorption following orthodontics with and without alveolar corticotomy. J Dent Res 2002; 80: 301.

[26] McFadden WM, Engstrom C, Engstrom H, Anholm JM. A study of the relationship between incisor intrusion and root shortening. Am J Orthod Dentofacial Orthop 1989; 96: 390-6.

[27] Little RM. Stability and relapse of dental arch alignment, In: Burstone CJ, Nanda R, Eds. Retention and stability in orthodontics. Philadelphia, Saunders 1993; p. 97-106.

[28] Nazarov AD, Ferguson DJ, Wilcko WM, Wilcko MT. Improved retention following corticotomy using $\mathrm{ABO}$ objective grading system. J Dent Res 2004; 83: 2644.

[29] Fischer TJ. Orthodontic treatment acceleration with corticotomyassisted exposure of palatally impacted canines. Angle Orthod 2007; 77: 417-20. 
[30] Vanarsdall RL Jr. Transverse dimension and long-term stability. Semin Orthod 1999; 5: 171-80.

[31] Yen SL, Yamashita DD, Kim TH, Baek HS, Gross J. Closure of an unusually large palatal fistula in a cleft patient by bony transport and corticotomy-assisted expansion. J Oral Maxillofac Surg 2003; 61: 1346-50.

[32] Lindner A. Longitudinal study on the effect of early interceptive treatment in 4-year-old children with unilateral crossbite. Scand J Dent Res 1989; 97: 432-38.

[33] Brin I, Ben-Bassat Y, Blustein Y, et al. Skeletal and functional effects of treatment for unilateral posterior crossbite. Am J Orthod Dentofacial Orthop 1996; 109: 173-79.

[34] Kanno T, Mitsugi M, Furuki Y, Kozato S, Ayasaka N, Mori H. Corticotomy and compression osteogenesis in the posterior maxilla for treating severe anterior open bite. Int J Oral Maxillofac Surg 2007; 36: 354-57.

[35] Moon CH, Wee JU, Lee HS. Intrusion of overerupted molars by corticotomy and orthodontic skeletal anchorage. Angle Orthod 2007; 77: 1119-25.

[36] OliveiraDD, de Oliveira BF, de Araújo Brito HH, de Souza MM, Medeiros PJ. Selective alveolar corticotomy to intrude overerupted molars. Am J Orthod Dentofacial Orthop 2008; 133: 902-8.

[37] Hwang H, Lee K. Intrusion of overerupted molars by corticotomy and magnets. Am J Orthod Dentofacial Orthop 2001; 120: 209-16.

[38] Yao CC, Wu CB, Wu HY, Kok SH, Chang HF, Chen YJ. Intrusion of the overerupted upper left first and second molars by miniimplants with partial-fixed orthodontic appliances: a case report. Angle Orthod 2004; 74: 550-7.

[39] Sherwood KH, Burch JG, Thompson WJ. Closing anterior open bites by intruding molars with titanium miniplate anchorage. Am J Orthod Dentofacial Orthop 2002; 122: 593-600.

[40] Enacar A, Pehlivanoglu M, Akcan CA. Molar intrusion with a palatal arch. J Clin Orthod 2003; 37: 557-9.

[41] Iino S, Sakoda S, Miyawaki S. An adult bimaxillary protrusion treated with corticotomy-facilitated orthodontics and titanium miniplates. Angle Orthod 2006; 76: 1074-82.
[42] Spena R, Caiazzo A, Gracco A, Siciliani G. The use of segmental corticotomy to enhance molar distalization. J Clin Orthod 2007; 41: 693-9.

[43] Lee JK, Chung KR, Baek SH. Treatment outcomes of orthodontic treatment, corticotomy-assisted orthodontic treatment, and anterior segmental osteotomy for bimaxillary dentoalveolar protrusion. Plast Reconstr Surg 2007; 120: 1027-36.

[44] Nishida M, Iizuka T, Itoi S, Hyo Y, Ono T. Clinical study of corticotomy by Kole's method. J Jpn Oral Surg Soc 1986; 3: 81-4.

[45] Kwon HJ, Pihlstrom B, Waite DE. Effects on the periodontium of vertical bone cutting for segmental osteotomy. J Oral Maxillofac Surg 1985; 43: 952-5.

[46] Dorfman HS, Turvey TA, Hill C. Alterations in osseous crestal height following interdental osteotomies. Oral Surg Oral Med Oral Pathol 1979; 48: 120-5.

[47] Oztürk M, Doruk C, Ozeç I, Polat S, Babacan H, Biçakci AA. Pulpal blood flow: effects of corticotomy and midline osteotomy in surgically assisted rapid palatal expansion. J Craniomaxillofac Surg 2003; 31: 97-100.

[48] Liou EJ, Figueroa AA, Polley JW. Rapid orthodontic tooth movement into newly distracted bone after mandibular distraction osteogenesis in a canine model. Am J Orthod Dentofacial Orthoped 2000; 117: 391-8.

[49] Owman-Moll P, Kurol J, Lundgren D. Continuous versus interrupted continuous orthodontic force related to early tooth movement and root resorption. Angle Orthod 1995; 65: 395-402.

[50] Harry MR, Sims MR. Root resorption in bicuspid intrusion: a scanning electron microscope study. Angle Orthod 1982; 52: 235-58.

[51] Kvam E. Scanning electron microscopy of tissue changes on the pressure surface of human premolars following tooth movement. Scand J Dent Res 1972; 80: 357-68.

[52] McFadden WM, Engstrom C, Engstrom H, Anholm JM. A study of the relationship between incisor intrusion and root shortening. Am J Orthod Dentofacial Orthop 1989; 96: 390-6.

(C) Hassan et al.; Licensee Bentham Open.

This is an open access article licensed under the terms of the Creative Commons Attribution Non-Commercial License (http://creativecommons.org/licenses/by-nc/3.0/) which permits unrestricted, non-commercial use, distribution and reproduction in any medium, provided the work is properly cited. 